\title{
EL TEMA DE LA SOLEDAD EN CONRAD
}

Por Ilda Cádiz Ávila

A Joseph Conrad le irritaba que le describieran como "escritor del mar". Según él, escribía sobre "la vida en el mar", interesándole primordialmente las reacciones de los hombres y la resistencia de los barcos en su lucha contra la naturaleza desatada en los océanos.

Uno de sus temas favoritos es lo que sucede a la integridad moral de un hombre al verse puesta, de modo inesperado, ante miles de ojos. En ese aspecto se acerca a Herman Melville, pero se distancia de Jack London, con quienes forma una trilogía de escritores que hicieron del mar su campo de caza literaria, si bien Conrad disfraza sus experiencias personales vistiéndolas con ropajes que simulan seres ajenos o distintos a él. Es cierto que está retratado en sus obras, pero se necesita leerlas todas para rescatar alguna faceta que revele al verdadero Conrad. En cada protagonista asoma una parte suya, a veces un doble, y porque no puede escapar de esa obsesión, casi todos sus héroes tropiezan con un alter ego, una contrapartida, generalmente una imagen negativa. Es lo que hace de Jim ("Lord Jim"), de Kurtz ("El Corazón de las Tinieblas"), de Razumov ("Bajo la Mirada de Occidente"), de Arsat ("La Laguna"), del príncipe Karain ("Karain"), del capitán anónimo ("El Partícipe Secreto"), personajes controvertidos, desmenuzados con escalpelo y bajo microscopio por los estudiosos. Al final, no se conocerá a fondo al emigrante polaco Jozef Teodor Konrad Korzeniowski que se convirtió en el escritor nacionalizado inglés Joseph Conrad.

Conrad nació el 3 de diciembre de 1857 en Berdiczew, en Podolia, una de las provincias ucranianas de Polonia - por entonces bajo el dominio de la Rusia zarista-, hijo único de Apollo Korzeniowski y de Evelina Bobrowska. Apollo, intelectual, de buena situación económica pero, por sobre todo, patriota, arriesgó cuanto le pertenecía, posición, seguridad, salud, futuro, no únicamente los suyos 
sino los de su esposa e hijo en su lucha contra el invasor ruso, y perdió. En 1863 fue condenado al destierro en Vologda, al norte de Rusia, a donde le siguió su familia. Los sufrimientos ocasionaron la muerte de Evelina en 1865 cuando Jozef contaba apenas siete años. En 1869 murió Apollo, honrado por el pueblo polaco como héroe nacional, y Jozef quedó bajo la tutela de su tío materno Tadeusz Bobrowski. Es ese pariente solterón el que se entrevé en varios personajes de Conrad y es quien brindó protección y consejos al sobrino cuando éste dispuso emprender su propio camino solo, "solo, totalmente solo, solo en un ancho mar", como el Viejo Marinero de Coleridge.

Conrad encarna un tipo especial en la literatura inglesa. En primer lugar, por no haber nacido dentro del imperio británico -insular o colonial- ni ser el inglés el idioma que hablara desde la infancia. Luego, llama la atención que un muchacho, que provenía del interior de Polonia, no ambicionara otra carrera que la de marino mercante $y$, de los idiomas que dominó, fuera el inglés el que se adentró en su conciencia y, como dijera más tarde, hasta pensaba en ése, aunque jamás adquirió el acento.

En el siglo xIx Polonia se relacionaba más con Francia y el joven Jozef estudió francés en el colegio; sin embargo, llegó a escribir el inglés con maestría tal que el poeta Robert Graves pudo comentar que Conrad escribió demasiado bien en un idioma adoptado. Tal vez influyera el hecho de que su padre tradujera algunas obras inglesas, entre ellas, "Dos Caballeros de Verona", de Shakespeare, pero el lenguaje que Jozef aprendió a hablar primero provino de los marineros y empleados del puerto en Marsella, ciudad adonde llegó recomendado por su tío a amistades bien relacionadas, tanto en el ambiente comercial naviero como en los círculos revolucionarios.

Conrad se mostró reticente acerca de sus años en Marsella; no obstante, se sabe que estuvo involucrado en contrabando de armas a favor de los carlistas en España, episodio que forma parte de su novela "La Flecha de Oro", en la cual presenta al capitán Blunt, uno de sus personajes solitarios, misterioso, introvertido, insomne y desesperadamente enamorado de doña Rita, la poderosa intermediaria de los realistas.

La carrera literaria de Conrad se inició con el cuento "El Piloto Negro", escrito entre 1884 y 1886, y concluyó con la novela "Suspenso", comenzada en 1920 y en la cual seguía trabajando al morir por paro cardíaco el 3 de agosto de 1924.

El comentarista conradiano Leo Gurko dice en su libro "Gigante en el Exilio" que había algo de profético en Conrad, considerando que la temática de sus novelas "Nostromo". "El Agente Secreto" y "Bajo la Mirada de Occidente", escritas en 1903, 1906 y 1910, respectivamente, son las revoluciones en Sudamérica, el terrorismo en Inglaterra y el enfrentamiento ideológico del imperialismo ruso con los grupos libertarios disidentes en la clandestinidad.

Si Conrad describe en detalle los rasgos físicos de algunos de sus protagonistas 
es para destacar su soledad. Así ocurre con Jim, con Kurtz, con Blunt, con Almayer de "La Locura de Almayer", con Willems de "El Paria de las Islas", con Heyst de "Victoria". Son ellos los personajes más solitarios y patéticos de las historias de Conrad. Si trasuntan su propia soledad, el autor jamás lo expresa abiertamente. Tal vez ella comenzara con las ausencias del padre a causa de sus actividades antizaristas, agravada más tarde por la pérdida de la madre. A los diecisiete años Conrad abandonó Polonia y sólo volvió como turista, acompañado de su familia, precisamente cuando estallaba la Primera Guerra Mundial.

Otra particularidad en los personajes de Conrad: los describe con atuendos y nombres significativos, vistiéndolos pulcramente al comienzo de sus relatos, como Jim, por ejemplo, siempre de blanco inmaculado, para terminar dejándolos hundidos en el lodo. Kurtz se basa en cierto belga de apellido Klein y Conrad transforma "Klein" (en alemán, pequeño, poco), en Kurtz ("kurz", corto). El marino Singleton, de "El Negro del Narciso", es el "single" (en inglés, solo, único), que no se contamina con el mal del motín. El capitán Whalley de "El Cabo de la Cuerda" es comparado por su piloto Sterne a una "whale" (ballena). Los Gould, que suena como "gold", oro, la rica familia de "Nostromo" son dueños de minas en Costaguana, una república de Sudamérica. Alex Heyst, cuyo apellido rima con Christ en inglés, en la novela "Victoria", se inmola por amor, no a la humanidad, sino porque ya no podría vivir solo, después que ha muerto en sus brazos la mujer que lo amó, una vagabunda que él rebautizara como Lena (parte del nombre de la pecadora Magdalena).

Los simbolismos abundan en las obras de Conrad: la lucha entre el bien y el mal; la naturaleza y el hombre; la debilidad recóndita de una persona disimulada bajo la apariencia de fortaleza. Los héroes son vulnerables, las heroínas les superan en resistencia al destino, al medio ambiente, a los vaivenes de los sentimientos. Son igualmente solitarias, tanto las intrínsecamente bondadosas - como Mrs. Gould de "Nosotros", o Natalie Haldin, de "Bajo la Mirada de Occidente"- como las otras, las malévolas, entre las cuales destaca la esposa mestiza de Almayer, o las apáticas, las frías y huecas, como la señora Travers de "Rescate", o la señorita Moorsom de "El Colono de Malata".

Nada puede compararse con la soledad que se introduce en el espíritu de los protagonistas masculinos y va carcomiéndoles la voluntad de vivir y no hallan espacios más apropiados - por lo menos en los tiempos cuando la aviación no dominaba el aire- que el mar o la selva. En algunas historias las tragedias se desarrollan en tierra firme, pero siempre los océanos o los ríos están cercanos. El interés apunta a la sicología del hombre, hurgando en el fondo de su alma y recorriendo los vericuetos de su mente, puestos al desnudo contra el fondo de la naturaleza. Lo que cree descubrir lo expresa a través de las dos últimas palabras de Kurtz: "¡El horror! ¡El horror!", o en la confesión de Jim después de atestiguar ante la comisión naval que juzga su cobardía en el naufragio del "Patna": "¡Es... el 
infierno!", o en la sordera absoluta que los revolucionarios rusos en el exilio ocasionan a golpes al traidor Razumov en "Bajo la Mirada de Occidente", condenándolo al aislamiento sin fin, a la marginación de los problemas de su pueblo que, en el fondo de su conciencia, había deseado. Tal vez esa sordera representa tanto el alejamiento de Conrad de su patria y sus complicaciones, como de la religión católica en que fue criado y que abandonó a los catorce años de edad.

¿Qué encuentra el hombre cuando llega al corazón de sus propias tinieblas? EI paralelo entre el viaje al centro del inconsciente y al de una selva o de un huracán en el océano, la marcación del personaje por el doble que se entromete en su vida, están presentes en las historias más destacadas de Conrad. A ellos se añaden otros elementos significativos que contribuyen a volverlos solitarios: la traición, el remordimiento, la expiación. Lord Jim, el príncipe malayo Karain, Kirylo Razumov, Peyrol de "El Pirata", el oficial francés de "Alma de Guerrero", son algunos ejemplos de esa secuencia.

En una escala de grados, Jim está en la cima de la soledad; jamás deja de vestir de blanco impecable, pero, como dice Conrad, no es sino un pelotón de arcilla que no quiere confesarse a sí mismo que es débil y cobarde. Uno es el Jim físicamente hermoso y seguro de sus reacciones correctas en el momento crucial; el otro Jim dentro de él, empujado, vencido, cae... "como a un pozo, a un agujero profundo eternamente...". Junto al capitán y otros dos desertores blancos, Jim huye del barco que - suponen - se hundirá irremediablemente con todos sus pasajeros, ignorando que el "Patna" es salvado por un capitán francés que lo lleva a puerto casi intacto. Es ese francés quien adivina el secreto de Jim: "Uno no muere de... de tener miedo". Jim sigue viviendo, alejándose cada vez más de los blancos que conocen su verdad y se interna en la selva malaya en busca de anonimato, olvido, paz, soledad. Sin embargo, siempre aparece alguien que divulga su historia y el peregrinaje debe continuar, hasta alcanzar el último punto de la jungla y de su propia conciencia. Jim vive porque tiene miedo y el Tuan Jim, el Lord Jim de blanco, casi rey y juez entre los nativos, considerado el más valiente, el justo, el infalible, un día se enfrenta a la oportunidad de redimirse, ante sí mismo, y esta vez no vacila y acepta cara a cara el tiro que borra su pecado.

Después de la soledad de Jim está la de Kurtz, el culto empleado de confianza de una compañía belga explotadora de marfil en el Congo, y que termina atrapado por el embrujo de la jungla hasta convertirse en amo de los nativos, adorado y temido como dios blanco al que se ofrecen sacrificios y ritos aberrantes. Conrad lo conoció en su viaje río arriba por el Congo belga en 1890 y su historia debió impresionarlo tan hondamente que la desdobló para crear dos narraciones consecuentes. La relación Jim-Kurtz se comprende mejor si se toma en cuenta que Conrad interrumpió la producción de "Lord Jim" para escribir "El Corazón de las Tinieblas". En ambas el narrador es Charles Marlow, intérprete de las experiencias yopiniones de Conrad, como lo es en "Juventud", que precede a "El Corazón de las 
Tinieblas". El productor cinematográfico Francis Ford Coppola aprovechó el Kurtz de Conrad para convertirlo en el americano enloquecido en la selva vietnamita de "Apocalipsis Ahora", sin lograr el impacto que el solitario Kurtz produce en el lector de la obra conradiana.

Otro personaje que cae al abismo de la soledad es Razumov, el joven estudiante de filosofía de la Universidad de San Petersburgo, huérfano, hijo bastardo de un noble ruso que lo protege sin revelarle la verdad. Razumov - como Jim- tiene planeado perfectamente su futuro, pero también sobre él actúan los Poderes Tenebrosos de Jim: la traición y la cobardía. Su condiscípulo Haldin está involucrado en el asesinato de un alto personaje ruso y acude a Razumov para que le oculte, pero éste lo delata, no por maldad, sino porque le arruina sus planes. Desde ese momento no tiene otro porvenir que aceptar ser espía del gobierno zarista entre los exiliados en Ginebra, presentándose ante ellos como amigos de Haldin, cuya muerte en la horca le ha convertido en héroe. El amor que despierta en Razumov, Natalie, hermana de Haldin, agudiza su sentimiento de culpa, a la par que le hace soñar con la redención, como a Jim. Pero, al revés de éste, que encara la muerte para acabar con su soledad, Razumov se ve condenado a vivir totalmente sordo $y$ más solitario que antes.

Conrad no da apellido a Jim ni nombre de pila a Kurtz. Entre todos los personajes claves de sus historias, hay uno anónimo: el capitán de "El Partícipe Secreto", tan anónimo como su barco; en cambio identifica como Leggatt al marino fugitivo del "Séfora" que el capitán anónimo esconde en su cabina, a pesar de saber que dio muerte a un tripulante. La historia se basa en un caso verídico que Conrad conoció de oídas y la simpatía que el narrador obliga al lector a sentir por el oficial culpable presume la parcialidad del escritor. El capitán se siente solo, un novato tanto para su barco como para la tripulación, y desde el primer momento siente que Leggatt es su doble, comparte con él su comida y sus ropas, aun le entrega dinero y arriesga la seguridad de su barco para dejar al fugitivo lo más cerca de una playa. Sólo cuando lo cree a salvo, el capitán sin nombre recupera la unidad de su yo y se siente libre y capacitado.

En cada una de sus cuarenta y cuatro obras Conrad introduce un personaje que, por diversas razones, no consigue avenirse con los demás. A algunos, como a Kaspar Almayer, de "La Locura de Almayer", a Peter Willems, de "El Paria de las Islas" -novelas correlacionadas-, la tragedia de su desgaste moral que les aparta de sus congéneres blancos, los lleva a la muerte. La soledad de otros radica en la tortura de callar una pasión (el capitán Roderick de "Chance"), en la conservación de una imagen de integridad ("Lord Jim"), en ocultar un defecto físico (la progresiva ceguera del capitán Whalley en "El Cabo de la Cuerda"), el secreto de los planes terroristas de Verloc ("El Agente Secreto").

La mayoría de las historias están ambientadas en las regiones sudasiáticas, pero Conrad también atravesó el Cabo de Hornos y obtuvo material para obras con 
trasfondo sudamericano. Un cuento, "Gaspar Ruiz", ocurre en Chile, durante la guerra entre patriotas y realistas, a comienzos de la segunda década del siglo $x \mid x, y$ en él hace referencias a figuras como San Martín, Lord Cochrane, los Carrera, y lugares como Valparaíso, Santiago, Linares, el Biobio, la cordillera y el sur de Chile. Tal vez Conrad oyó la historia de Benavides, conocido en los tiempos de la guerra a muerte, y aprovechó detalles para crear el personaje de Gaspar Ruiz, otro de los desambientados conradianos.

La novela "Nostromo", publicada en 1904 y considerada su mejor obra, es la historia de una revolución en América del Sur a fines del siglo pasado y en ella menciona a Valparaíso, Atacama, las minas de nitrato en el norte y un señor de apellido Edwards. Los personajes y acontecimientos de "Nostromo" bien pueden representar la política actual. Es también la novela con el mayor número de caracteres acosados por el dolor de la soledad: Gian Battista Nostromo, capataz de las minas Gould, considerado incorruptible y fiel a sus amos, los traiciona y se apodera de un cargamento de plata; el señor y la señora Gould, a pesar del amor que les une, se saben separados por sus distintos conceptos sobre el valor del dinero; Martin Decoud, atormentado por su amor imposible por la joven Antonia Avellanos - la heroína favorita de Conrad-, se suicida. Está, además, el Dr. Monygham que debe ocultar su amor por la señora Gould porque se sabe indigno de amar, por cobarde, traidor e incapaz de soportar la tortura física.

Un solitario especial: el negro del "Narciso". Es el único negro en una tripulación de blancos y es también el único en el barco que Conrad identifica con nombre completo, James Wait, al resto se le conoce por nombre de pila, apellido o apodo. Tras su arrogancia, cinismo y teatralidad, Wait oculta su soledad, su diferencia, y se llega al final de la obra sin saber si así se llamaba, pues al examinar sus papeles, a su muerte, no se le encuentra identificación.

Marlow, el capitán Charles Marlow, narrador en tres de los relatos de Conrad y participante en un cuarto es, en esencia, Conrad mismo, representando la dualidad que caracteriza a sus personajes: Marlow-Conrad; Marlow-Jim; Marlow-Kurtz; Jim-Capitán Brown; Razumov-Haldin y, sobre todo, el anónimo capitán de un barco anónimo y el fugitivo Leggatt. Conrad presenta a Marlow en "Juventud", relato de su primer viaje a los mares de Oriente; es la primera persona en "El Corazón de las Tinieblas" $y$, desde el Capítulo $5^{\circ}$, en "Lord Jim". En la cuarta narración, "Chance", escrita en 1912, Marlow es anfitrión del narrador y, como solterón empedernido, desborda su opinión antifeminista. Flora de Barral es uno de los personajes notables de Conrad por su feminidad y, como la señora Gould, resignada, pero para Marlow las mujeres no tienen honor ni decencia - en el sentido masculino-, no son racionales pero sí agudas, son pasivas con una inercia enigmática y, por tanto, amenazadora, y si no representaran una fuerza de la naturaleza, ciega en su vigor y caprichosa en su poder, no habría por qué desconfiar de ellas.

El éxito no llegó fácil al bolsillo de Conrad. La malaria que contrajo en el Congo 
belga en 1890 lo obligó a retirarse de la vida marina en 1896, dedicándose a escribir. Produjo treinta y dos relatos antes que la edición de "Chance" en Estados Unidos en 1914 le acarreara renombre y dinero. Sin embargo, la fama y el bienestar no parecieron influir en favor de la calidad de su producción literaria hasta su muerte en 1924 en Kent, Inglaterra. Lo mejor de su obra pertenece al período anterior a 1910. "El Corazón de las Tinieblas" y "Lord Jim" fueron escritas entre 1898 y 1900 y "El Partícipe Secreto" en 1909 y conforman la trilogía enigmática de Conrad, la trilogía de la soledad del pecador en medio de la jungla-conciencia; el careo de la verdad al borde del abismo-conciencia; el revés del espejo de la imagenconciencia. Sólo la muerte es compasiva con el solitario. 